\title{
ESTIMATION OF CHLOROPHYLL-A CONCENTRATION IN SAMPALOC LAKE USING UAS MULTISPECTRAL REMOTE SENSING AND REGRESSION ANALYSIS
}

\author{
R. M. G. Maravilla ${ }^{1}$, J. P. Quinalayo ${ }^{1}$, A. C. Blanco ${ }^{1,2}$, C. G. Candido ${ }^{2}$, E. V. Gubatanga ${ }^{2}$, K. D. V. Ticman ${ }^{2}$ \\ ${ }^{1}$ Department of Geodetic Engineering, University of the Philippines Diliman \\ 2 Training Center for Applied Geodesy and Photogrammetry, University of the Philippines Diliman \\ rgmaravilla1@up.edu.ph, jerickquinalayo@yahoo.com, acblanco@up.edu.ph, chriscandido93@gmail.com, \\ evgubatanga@gmail.com,kvticman@gmail.com
}

\section{Commission IV}

KEY WORDS: Reflectance, algae biomass, band ratioing, linear regression, water quality, pixel values

\begin{abstract}
:
Sampaloc Lake is providing livelihood for the residents through aquaculture. An increase in the quantity of fish pens inside the lake threatens its water quality condition. One parameter being monitored is microalgal biomass by measuring Chlorophyll-a concentration. This study aims to generate a chlorophyll-a concentration model for easier monitoring of the lake. In-situ water quality data were collected using chl-a data logger and water quality meter at 357 and 12 locations, respectively. Using Parrot Sequoia+ Multispectral Camera, 1496 of 2148 images were acquired and calibrated, producing $18 \times 18 \mathrm{~cm}$ resolution Green (G), Red(R), Red Edge (RE) and Near Infrared (NIR) reflectance images. NIR was used to mask out non-water features, and to correct sun glint. The in-situ data and the pixel values extracted were used for Simple Linear Regression Analysis. A model with 5 variables -- R/NIR, RE ${ }^{2}$, $\mathrm{NIR}^{2}, \mathrm{R} / \mathrm{NIR}^{2}$, and NIR/RE${ }^{2}$, was generated, yielding an $\mathrm{R}^{2}$ of 0.586 and RMSE of $0.958 \mu \mathrm{g} / \mathrm{l}$. A chlorophyll-a concentration map was produced, showing that chl-a is higher where fish pens are located and lowers as it moves away from the pens. Although there are apparent fish pens on certain areas of the lake, it still yields low chlorophyll-a because of little amount of residential area or establishments adjacent to it. Also, not all fish pens have the same concentration of Chlorophyll-a due to inconsistent population per fish pen. The center of the lake has low chlorophyll-a as it is far from human activities. The only outlet, Sabang Creek, also indicates high concentration of Chlorophyll-a.
\end{abstract}

\section{INTRODUCTION}

\subsection{Background of the Study}

Sampaloc Lake is the largest among the Seven Crater Lake of San Pablo, Laguna. It has an area of 104 hectares and a maximum depth of 27 meters. Because the lake is an inactive volcanic maar, nearly half of its depth has a shallow depression. The lake serves as a good income-provider for the fishermen as it contains tilapia and bangus. The lake also serves as a recreational place for the locals and the tourists as well.

In 2014, the Sampaloc Lake, together with six other crater lakes, was named by the Global Nature Fund as the Threatened Lake of the Year. This is due to the human activities like illegal squatting along the shores of the lake, construction of fish-pens and fish cages that are used for commercial purposes. This fish farming can cause depletion of dissolved oxygen that will definitely hard for the biodiversity in the lakes. (GNF, 2014). One of the symptoms of degraded water quality condition is the increase of algae biomass as measured by the concentration of Chlorophyll-a (Standard Methods for the Examination of Water and Wastewater, 2018).

A fast and efficient monitoring system can help for authorities to keep an eye on the lake's water quality. Maintaining Class-C water quality is a must for a lake to be safe enough for fishing.

\subsection{Objectives of the Study}

The objectives of this study are to develop a regression model for estimating Chlorophyll-a concentration from multispectral images acquired using an unmanned aerial system and to use the model to generate and to assess the Chlorophyll-a Concentration Map of Sampaloc Lake.

\subsection{Scope and Limitations of the Study}

This study used AAQ Water Quality Meter and CLW Data Logger to measure the Chlorophyll-a Concentration in Sampaloc Lake. 12 data points, for AAQ, and 357 data points, for CLW, with a good distribution all throughout the lake were collected. The Parrot Sequoia+ Multispectral Camera attached to eBee Sensefly Professional Mapping Drone were used to conduct five individual flights and collected 2148 high resolution images. The image resolution produced was 18 by 18 $\mathrm{cm}$.

The limitations of this study are it predicts the Chlorophyll-a concentration of Sampaloc Lake only by using Parrot Sequoia with bands Green, Red, Red Edge, and NIR. Also, a small part in the center of the map was obtained only through interpolation because $31 \%$ of the cameras were uncalibrated.

\section{REVIEW OF RELATED LITERATURES}

\subsection{Remote Sensing Project}

In a study entitled, "Spatial Analysis of Water Quality Using Unmanned Aerial System (UAS): A Study of Lake Palakpakin, San Pablo, Laguna, water quality parameters of Palakpakin Lake including Chlorophyll-a and Turbidity were estimated by using RGB camera and regression analysis. In this study, in-situ Chlorophyll-a concentration observation was obtained using water quality profiler (AAQ) and for the images, Sensefly eBee 
was used. The researchers performed linear regression using the band ratios from the Blue, Green, and Red reflectance bands. They concluded that the RGB bands and the number of points they used in this study were not enough in generating an Turbidity or Chlorophyll-a Concentration Model in Lake Palakpakin.

However, a study done in Taiwan entitled "Application of Multispectral Sensors Carried on Unmanned Aerial Vehicle (UAV) to Trophic State Mapping of Small Reservoirs: A Case Study of Tain-Pu Reservoir in Kinmen, Taiwan" by Hung-Ta Chou and Tung-Ching Su produced a good model for Tropic State Mapping of small reservoirs in Tain-Pu. They used RGB and NIR Sensors that were carried by UAS (unmanned aerial vehicle) and in situ sampling for this study.

\subsection{Sun Glint Correction}

One of the most serious problems encountered in remote sensing is the sun glint, or the specular reflection of sunlight on water. Sunglint occurs when the sunlight reflects off the water surface with the same angle where a sensor is viewing the surface. Sunglint correction is very necessary for it blocks the sighting of the sea bottom.

On a study entitled "Sun Glint Correction of High and Low Spatial Resolution Images of Aquatic Scenes: a Review of Methods for Visible and Near-Infrared Wavelengths", Hedleys Methodology was developed. Hedleys Methodology established the relationship between bands and NIR using linear regression of the pixel values of the reflectance maps.

\subsection{Band Ratioing}

Band Ratioing is one of the most useful image processing technique, as it utilises the relationship between different band to improve analysis. The DN value of the band is then divided to another band which will yield new sets of values. These new sets of values can interpret the images better by correcting shadows, etc. or bringing out features better. (Department of Geology, Aligarh Muslim University, n.d.)

The band ratio algorithm used to estimate the water quality parameters has different accuracy as stated in the correlation coefficient and the statistical significance of the study Development and application of remote sensing-based Chlorophyll-a concentration prediction model for complex coastal waters done by Hong Kong, Majid Nazeer and Janet E. Nichol.

\section{METHODOLOGY}

\subsection{Materials and Softwares Used}

A fieldwork happened last January 10, 2019 and two modes of data acquisition were done. For aerial image acquisition, we used Ebee Sensefly Professional Mapping Drone with a Parrot Sequioa+ Multispectral Camera attached to it. For in-situ data collection, Chlorophyll-a Data Logger, AAQ Water Quality Meter and a GPS were used.

The Ebee Sensefly is a fully autonomous mapping drone that can be used to capture high resolution aerial images. I can cover up to 12 square kilometer in a single automated mapping flight and only weighs 700 grams. Ebee senseFly has a cutting-edge autopilot ability that can manage a wide range of intelligent failsafe behaviours. (senseFly Ltd., 2009-2015)
The Parrot Sequoia Multispectral Camera has four multispectral sensors; Green, Red, Red 土and NIR band with a resolution of 1.2MP, an RGB camera with 16MP resolution, and a sunshine sensor. This camera is compatible with the Ebee Sensely Drone

The CLW is a miniature data logger that can measure Chlorophyll-a, Fluorescence, turbidity, and temperature. The CLW is controlled through the RS232-C port of a PC. The CLW records data along track and per time set interval. The setup requires start time and sampling interval. information such as measurement start time and calibration coefficients, and measured data will be gathered after deployment. (JFE Advantech Co.,Ltd, 2012)

The AAQ Water Quality Meter is ideal for profiling freshwater and saltwater, as it can measure depth, temperature, conductivity, salinity, turbidity, Chlorophyll, dissolved oxygen, $\mathrm{pH}$, Photo Quantum, and ORP. It comes with a Pro Model, Smart Handy and an Interface Model for processing. (JFE Advantech Co.,Ltd, 2012)

The Handheld GPS was used to record the coordinates of each AAQ data per station and also was used as a path check of the along track sampling. The softwares used to processed all gathered data were ArcMap, Pix4D, and XLStat

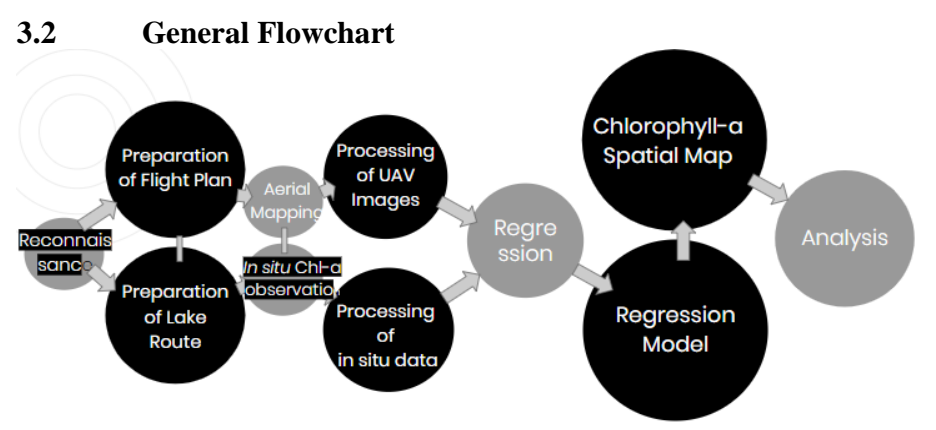

Figure 1. General Flowchart of the Research Process

\subsection{In-situ Data Gathering and Processing}

A raft was used as the mode of transportation along the lake because motor boats were not allowed in the lake. The Chlorophyll-a Data Logger (CLW) was attached to the raft in order to obtain the along-track measurements of chlorophyll-a. A total of 357 filtered water quality data were obtained. Since the CLW records data per second, the worksheet with recorded time of arrival per station was used to filter and select the chlorophyll-a value to be used per length interval.

The water quality profiler (AAQ) was also mounted on the raft. In order to get the chlorophyll-a reading per station, the AAQ was submerged for 3 meters and it records data for every 0.5 meter interval. The average of the data was used as the final chlorophyll-a value of the station. The GPS was used to record the coordinates of the station points. A total of twelve (12) station water quality data were obtained from AAQ. The route plan (Figure 9) was made in order to maximize the use of the equipment and to effectively cover the whole Sampaloc Lake as well.

The in-situ data observations were imported and plotted using ArcMap 10. The values both dataset are approximately ranging from 3 to $10 \mu \mathrm{g} / \mathrm{l}$ and coinciding with each other. 


\subsection{Initial Processing of UAV Data}

For the image acquisition, the Parrot Sequoia sensor was mounted on Sensefly eBee mapping drone. A total of 5 flights was done in order to cover the whole Sampaloc Lake. An overlap of $80 \%$ was also done. And the resulting pixel resolution is $18 \mathrm{~cm}$ by $18 \mathrm{~cm}$. The five flight data were processed in a single project using Pix4D Mapper.

The three processing stages in Pix4D Mapper include - Initial Processing, Point Cloud and Mesh generation, and Digital Surface Model, Orthomosaic and Index generation. For the Initial Processing, Double (2) Image Size for Keypoints Image Scale was used in order to improve the accuracy of the result since more features will be extracted for that option. Also, the calibration method used was Alternative as it is optimized for aerial nadir images with accurate geolocation and low texture content. For the Point Cloud and Mesh generation, all options are at default. On Digital Surface Model, Orthomosaic and Index generation, the resolution downsampling method used was $75 \%$ quantile, so that the pixel value that will be generated will not be affected by outliers.

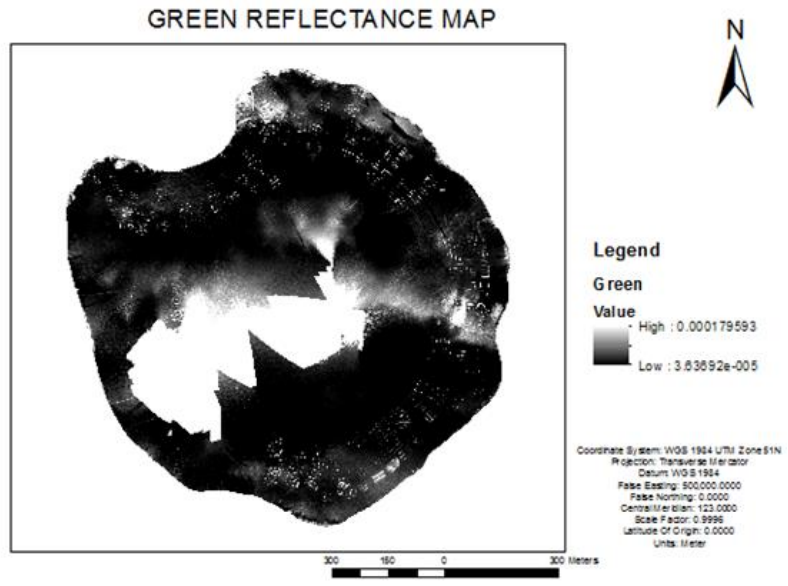

Figure 2: Green reflectance map

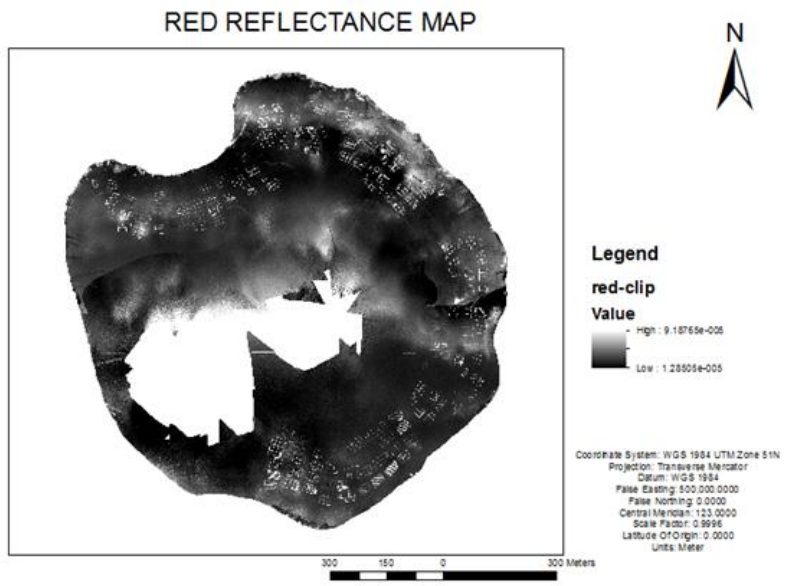

Figure 3. Red reflectance map

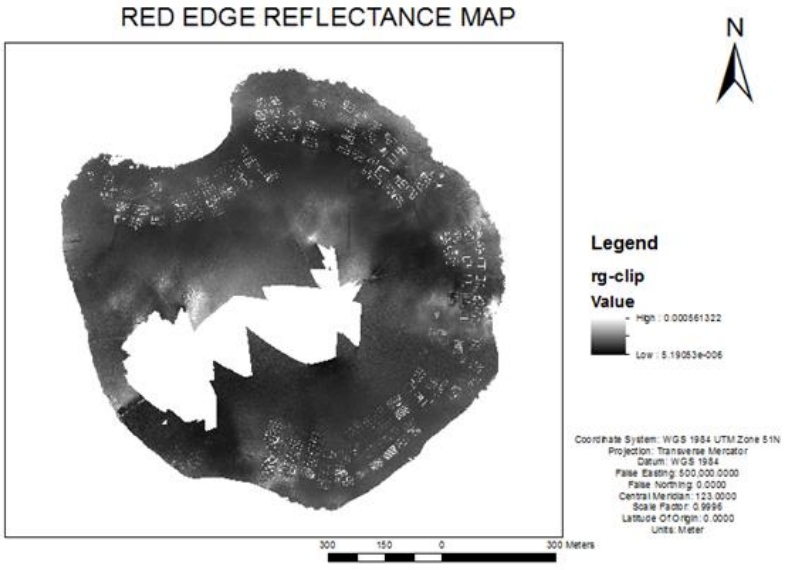

Figure 4. Red edge reflectance map

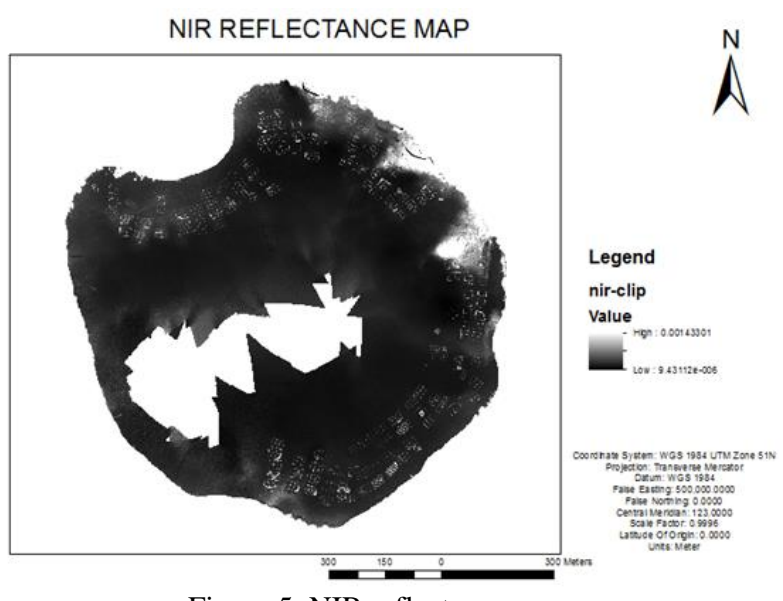

Figure 5. NIR reflectance map

Figure 2-5 shows the generated reflectance maps of the four bands - Green, Red, Red Edge, and NIR. In the generated reflectance maps, it is apparent that there are holes in the middle portion of the map. This is due to the cameras that were not automatically calibrated by Pix4D. Upon investigation based on the raw images, it can be seen that the middle portion contains mostly of water. The homogeneity of water and constantly changing surface makes it hard to gather enough key points that can calibrate a camera. Also, in the generated images there are pixel values that are higher than normal, and again upon investigation of the raw images, it was found out that these portions are affected by sunglint. The fish pens are also very visible due to high reflectance of its surface.

\subsection{Masking}

The NIR reflectance map was used for the sunglint correction of other bands. With that, fishpens and erroneous pixels were removed using reclassification and masking. The fishpens were removed together with pixels with the same pixel value or much greater as the fishpens. Natural Breaks (Jenks) was used as the classification method. The reclassified NIR reflectance map was filtered using "Extract by Attribute" in the Spatial Analyst Toolbox. Attributes 1 and 2 were retained as it doesn't contain the pixel values of the fish pens. Attributes 3 to 9 displayed the fishpen pixel as well as the pixels with abnormally high pixel values. Attributes 1 and 2 were then used to mask the initial NIR reflectance map. 


\section{EXTRACTEDWATER PIXELS}

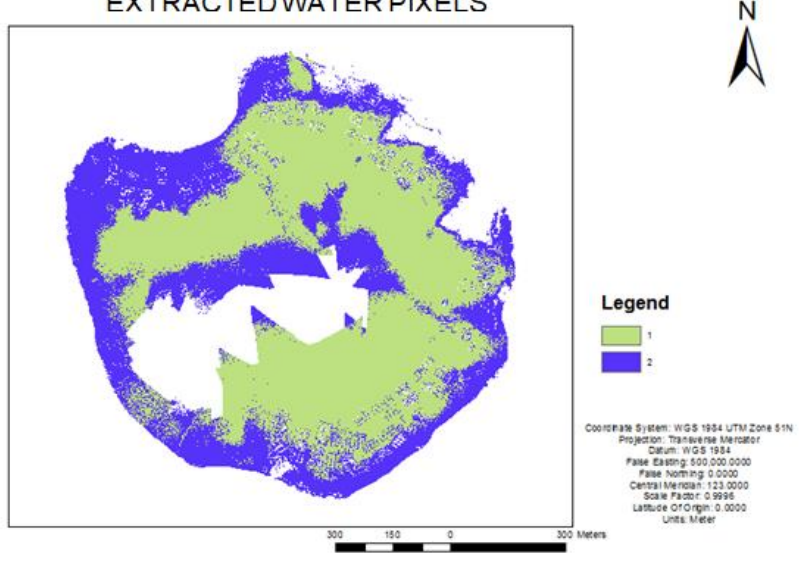

Figure 6. Extracted water pixels of NIR reflectance map

\section{6}

\section{Focal Statistics}

It is still apparent in the masked NIR reflectance map that there are noises present in the map. In order to eliminate those noises, focal statistics was used. It is assumed that in NIR Reflectance Map, water pixels have the minimum pixel values. With that, the neighborhood type that was used was circle with a radius of 10 cells and statistics type of "minimum".

\subsection{Sun Glint Correction}

One of the most serious problem encountered in remote sensing is the sun glint, or the specular reflection of sunlight on water. Sunglint occurs when the sunlight reflects off the water surface with the same angle where a sensor is viewing the surface. Hedleys Methodology was used to correct the sunglint:

$$
\mathrm{R}^{\prime} \mathrm{i}=\mathrm{Ri}-\text { bi (RNIR - RMIN) }
$$

where:

$$
(\mathrm{NIR}=0.000011)
$$

$$
\begin{array}{ll}
\mathrm{i} & =\text { band } \\
\mathrm{R}{ }^{\prime} \mathrm{i} & =\text { corrected pixel value of the band } \\
\mathrm{Ri} & =\text { initial pixel value of the band } \\
\mathrm{bi} & \text { = regression slope between band and NIR } \\
\mathrm{Rnir}=\text { pixel value in NIR } & \\
\mathrm{Rmin}= & \text { minimum NIR pixel value of deep waters }
\end{array}
$$

In order to obtain the regression slope between band and NIR, sample points were created which is scattered where there are low, medium, and high sunglint. These sample points were used to extract the pixel values of each band and performed linear regression where NIR was the $\mathrm{x}$ variable, while the other bands were the $y$ variable.

\subsection{Extraction of Reflectance Bands Pixel Values}

The pixel values of the reflectance maps were extracted using the Spatial Analyst Tool. The data points from AAQ and CLW were used as the point bases. In order to directly compare the in situ data and then the reflectance value on a specific point. The extracted points were then imported to Microsoft Excel to be filtered.

The pixel values of the reflectance maps were extracted using the Spatial Analyst Tool. The data points from AAQ and CLW were used as the point bases. In order to directly compare the in situ data and then the reflectance value on a specific point. The extracted points were then imported to Microsoft Excel to be filtered.

\subsection{Linear Regression}

Linear Regression was performed using XLStat in Microsoft Excel. A total of 173 in-situ points were used.The band ratios used can be seen in Table 1 .

\begin{tabular}{|l|l|l|l|}
\hline $\mathrm{G} / \mathrm{R}$ & $\mathrm{G}^{2}$ & $\mathrm{G} / \mathrm{NIR}^{2}$ & $\mathrm{RE} / \mathrm{NIR}^{2}$ \\
\hline $\mathrm{G} / \mathrm{RE}$ & $\mathrm{R}^{2}$ & $\mathrm{R} / \mathrm{G}^{2}$ & $\mathrm{NIR} / \mathrm{G}^{2}$ \\
\hline $\mathrm{G} / \mathrm{NIR}$ & $\mathrm{RE}^{2}$ & $\mathrm{R} / \mathrm{RE}^{2}$ & $\mathrm{NIR} / \mathrm{R}^{2}$ \\
\hline $\mathrm{R} / \mathrm{RE}$ & $\mathrm{NIR}$ & $\mathrm{R} / \mathrm{NIR}^{2}$ & $\mathrm{NIR} / \mathrm{RE}^{2}$ \\
\hline $\mathrm{R} / \mathrm{NIR}$ & $\mathrm{G} / \mathrm{R}^{2}$ & $\mathrm{RE} / \mathrm{G}^{2}$ & - \\
\hline $\mathrm{RE} / \mathrm{NIR}$ & $\mathrm{G} / \mathrm{RE}^{2}$ & $\mathrm{RE} / \mathrm{R}^{2}$ & - \\
\hline
\end{tabular}

Table.1 Band ratios used for Linear Regression

where:

$\begin{array}{lll}\mathrm{G} & = & \text { Green band } \\ \mathrm{R} & = & \text { Red band } \\ \mathrm{RE} & = & \text { Red Edge band } \\ \mathrm{NIR} & = & \text { NIR band }\end{array}$

\section{RESULTS AND DISCUSSION}

\subsection{Regression of Variable Chlorophyll-a Result}

The Chlorophyll-a is the dependent variable and the band ratios of the reflectance values will stand as the independent variables or the explanatory variables. 173 data points were used overall in linear regression with 123 points as data points for the creation of model and 50 points as points used for validation. 50 validation points were randomly selected from the list.For the linear regression, best model variable selection method was used with minimum of 1 variable and maximum of 5 variables selection with $95 \%$ confidence interval. In this linear regression, 5 variables were retained. Given the $\mathrm{R}^{2}, 60 \%$ of the variability of the dependent variable, Chlorophyll-a, is explained by the 5 remaining explanatory variables -- Red/NIR, Red Edge ${ }^{2}, \mathrm{NIR}^{2}$, Red/NIR ${ }^{2}$ and NIR/Red Edge ${ }^{2}$.

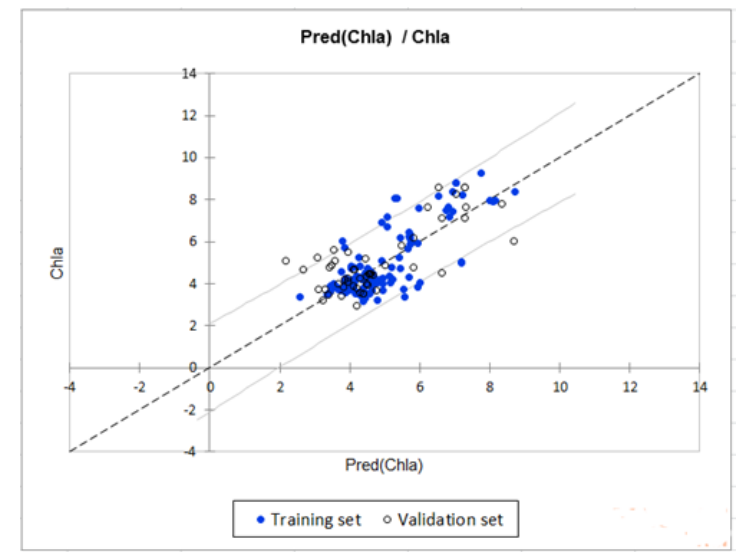

Figure 7. Graph of chlorophyll-a vs predicted chlorophyll-a values 
As seen in Figure 7, the graph between the in-situ Chlorophyll-a and the predicted Chlorophyll-a, majority of the values fall inside the confidence interval of $5 \%$.

The linear regression also yielded the equation:

$\mathrm{CHLA}=\mathrm{A}-\mathrm{B} *(\operatorname{Red} / \mathrm{NIR})-\mathrm{C}^{*}($ RedEdge 2$)+\mathrm{D} *(\mathrm{NIR} 2)$

$+\mathrm{E}^{*}(\mathrm{Red} / \mathrm{NIR} 2)-\left(\mathrm{F}^{*} \mathrm{NIR} / \mathrm{Red}\right.$ Edge 2$)$

where,

$\mathrm{A}=5.81567724374094$

$\mathrm{B}=12.3812880663368$

$\mathrm{D}=2203620046.43992$

$\mathrm{C}=5670534328.48428$

$\mathrm{E}=0.0002440565167366$

$\mathrm{F}=0.00000334181467821625$

The resulting equation was then performed using ArcMap 10's Raster Calculator function. Upon the production of the map, it then appears to be all black but upon checking, pixel values exist per cell. The stretch type of the values was then changed to minimum to maximum. The minimum value was then changed to 0 , and the maximum value was changed to 12 as to eliminate the erroneous pixel value. The resulting map can be seen in Figure 8.

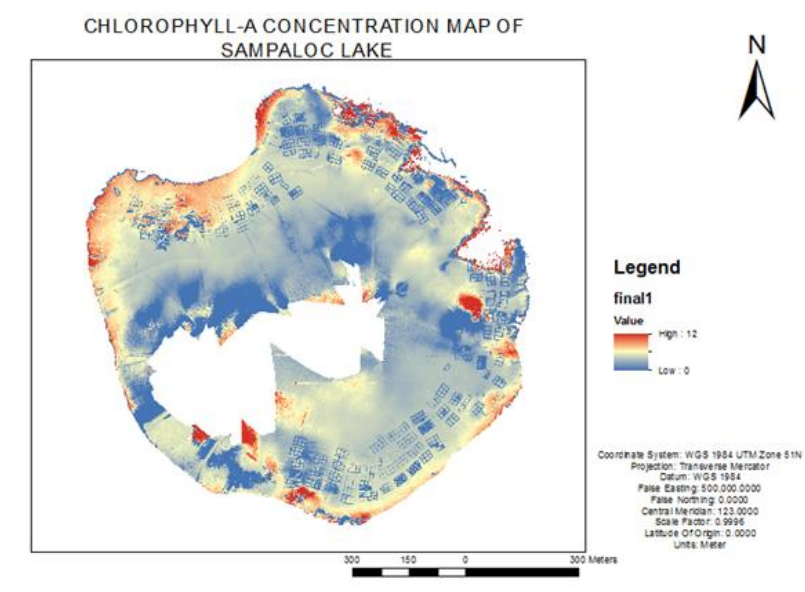

Figure 8. Chlorophyll-a concentration map of Sampaloc Lake from the generated model

\subsection{Kriging Interpolation}

For better visualization of the distribution of the Chlorophyll-a values, interpolation was done to fill up the no data areas and to reduce the erroneous values. Point shapefiles were created and distributed all over the map. Kriging Interpolation, a geostatical procedure, generated an estimated surface from the basis points created. Its algorithm included the idea that the points were spatially correlated in distance and direction.

After performing the Kriging Interpolation, a Chlorophyll-a Concentration Map of Sampaloc Lake was generated with values ranging from 1.63136 to $8.06701 \mathrm{ug} / \mathrm{L}$ as shown in Figure 9.

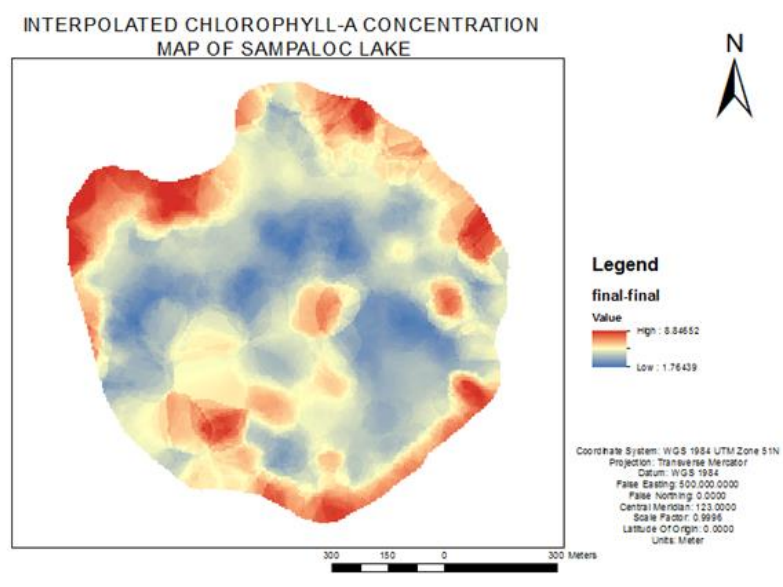

Figure 9. Interpolated chlorophyll-a concentration map of Sampaloc Lake

\subsection{Analysis}

The Chl-a concentration of the map is relatively higher where fish pens are located and lowers as it moves away from the pens. On the upper left part of the map, it is very evident that when it approaches towards the middle, the chlorophyll-a concentration lowers, hence the blue color. Although there are apparent fish pen on the upper side, and on the right side, there is little amount of residential area or establishments adjacent to it.

Also, not all fish pens has the same concentration of Chlorophyll-a. it was reported before that there are illegal fish pens that are being overfed, and those fish cages are also crowded. The center of the lake has relatively low chl-a concentration. This portion of the lake is far from human activities. The location of the only outlet, Sabang Creek, of the Sampaloc Lake also indicates high concentration of Chlorophyll-a.

\section{CONCLUSIONS AND RECOMMENDATIONS}

The ratios between Red, Red Edge, and NIR bands has enough correlation with Chlorophyll-a to generate a model for Chlorophyll-a Concentration in Sampaloc Lake . The model has an $\mathrm{R}^{2}$ of 0.586 and RMSE of $0.958 \mathrm{ug} / \mathrm{L}$, resulted from Linear Regression. The Sampaloc Lake Chlorophyll-a Concentration Map values are ranging from 1.63136 to 8.06701 ug/L.. The values coincide with the in situ data as the chla vs pred_chl-a graph shows. The lake is still far from the critical level, nuisance bloom, of $20 \mathrm{ug} / \mathrm{L}$ (Kristi Manahan, Water Quality Standards, 2017).

The researchers recommend finding an image calibration technique that will work well on geolocated images for a complete generation of the reflectance maps.

For further research, we suggest to have a statistical analysis on the Chlorophyll-a distribution of the lake and to test the generated model again on Sampaloc Lake but on a different time or to a lake with similar properties. 


\section{ACKNOWLEDGEMENTS}

We would like to offer our deepest gratitude to the Environmental Systems Applications of Geomatics Engineering (EnviSAGE) for letting us use the research instruments and the computer workstation for processing the data. We are also extremely grateful for our families for the never-ending love and support. We are thankful for all of the sacrifices of our parents for us to be in the position that we are in today. To our dear siblings for the care and support and for giving us the extra push to finish our thesis. To all of our friends and loved ones, for being an inspiration to us, we thank you. And lastly, we would like to thank UP - Diliman for teaching us to strive for honour and excellence.

\section{REFERENCES}

Algal bloom. (n.d.). Encyclopedia of Environmental Change. doi:10.4135/9781446247501.n129

Bongcac, and Toledo (2016). Spatial Analysis of Water Quality Using Unmanned Aerial

System (UAS): A Study of Lake Palakpakin, San Pablo, Laguna. University of the Philippines - Diliman. Quezon City, Philippines

Brillo (2017). The Governance of the Seven Crater Lakes, San Pablo City, Philippines. Asian

Journal of Water, Environment and Pollution (vol. 14, no. 2, pp. 13-25). New Delhi. Capital Publishing Company.

CHLOROPHYLL | definition in the Cambridge English Dictionary. (n.d.). Retrieved May,

2019, from https://dictionary.cambridge.org/us/dictionary/english/chloroph yll

Customers. (2014, May 12). Chlorophyll a. Retrieved May, 2019, from https://www.biology-

online.org/dictionary/Chlorophyll_a

Department of Geology, Aligarh Muslim University. Band Ratioing. Retrieved May 2019,

from http://www.geol-amu.org/notes/m14a-4-8.htm

Finch, Samuel, and Lane (2014). Principles of Crop Production - "Plants". Lockhart \&

Wiseman's Crop Husbandry Including Grassland (Ninth Edition, pp. 3-26). Oxford, UK: Woodhead Publishing.

Flynn, K., \& Chapra, S. (2014). Remote Sensing of Submerged Aquatic Vegetation in a

Shallow Non-Turbid River Using an Unmanned Aerial Vehicle. Remote Sensing, 6(12), 12815-12836. doi:10.3390/rs61212815

Garg, V., \& Chaubey, A. I. (n.d.). Effect Of Suspended Sediment Distribution On Spectral

Reflectance. Total Maximum Daily Load (TMDL) Environmental Regulations II. doi:10.13031/2013.15549

Ha, N. T., Thao, N. T., Koike, K., \& Nhuan, M. T. (2017) Selecting the Best Band Ratio to

Estimate Chlorophyll-a Concentration in a Tropical Freshwater Lake Using Sentinel 2A Images from a Case Study of Lake Ba Be (Northern Vietnam). ISPRS International Journal of GeoInformation, 6(9), 290. doi:10.3390/ijgi6090290
Hose, G. C., Murray, B. R., \& Eamus, D. (2004). Water quality guidelines to protect

groundwater-dependent ecosystems. Ecological Management and Restoration, 5(1), 78-80. doi:10.1111/j.14428903.2004.180-6.x

JFE Advantech Water Quality Meter AAQ Rinko. (n.d.). Retrieved May, 2019, from http://www.analyticalsolns.com.au/product/aqua_quality_meter. html

Kay, Hedley and Lavender (2009). Sun Glint Correction of High and Low Spatial Resolution

Images of Aquatic Scenes: a Review of Methods for Visible and Near-Infrared Wavelengths. Remote Sensing (Volume 1 Issue 4, pp. 697-730).

Martin, J., Eugenio, F., Marcello, J., \& Medina, A. (2016). Automatic Sun Glint Removal of

Multispectral High-Resolution Worldview-2 Imagery for Retrieving Coastal Shallow Water Parameters. Remote Sensing, 8(1), 37. doi:10.3390/rs8010037

Maximum Yield. (n.d.). What is Chlorophyll A? - Definition from MaximumYield. Retrieved

May, 2019 from

https://www.maximumyield.com/definition/789/chlorophyll-a

Nazeer, M., \& Nichol, J. E. (2016). Development and application of a remote sensing-based

Chlorophyll-a concentration prediction model for complex coastal waters of Hong Kong. Journal of Hydrology, 532, 8089. doi:10.1016/j.jhydrol.2015.11.037

n.d. (1993). Linear Regression. World Almanac and Book of Facts. Pharos Books; 125 Annv edition.

Overstreet, B. T., \& Legleiter, C. J. (2016). Removing sun glint from optical remote sensing

images of shallow rivers. Earth Surface Processes and Landforms, 42(2), 318-333. doi:10.1002/esp.4063

Ritchie, J. C., Zimba, P. V., \& Everitt, J. H. (2003). Remote Sensing Techniques to Assess

Water Quality. Photogrammetric Engineering \& Remote Sensing, 69(6), 695-704. doi:10.14358/pers.69.6.695

Sawyer, C. B., Privette, C. V., Koc, A., \& Koparan, C. (2018). In Situ Water Quality

Measurements Using an Unmanned Aerial Vehicle (UAV) System. Water, 10(3), 264. doi:10.3390/w10030264

senseFly Ltd. (2009-2015). eBee: senseFly SA. Retrieved May 2019, from senseFly:

https://www.sensefly.com/drones/ebee.html

Su, T.-C., \& Chou, H.-T. (2015). Application of Multispectral Sensors Carried on Unmanned

Aerial Vehicle (UAV) to Trophic State Mapping of Small Reservoirs: A Case Study of Tain-Pu Reservoir in Kinmen, Taiwan. Remote Sensing, 7(8), 10078-10097. doi:10.3390/rs70810078

Sváb, E., Tyler, A. N., Preston, T., Présing, M., \& Balogh, K. V. (2005). Characterizing the 
spectral reflectance of algae in lake waters with high suspended sediment concentrations. International Journal of Remote Sensing, 26(5), 919-928. doi:10.1080/0143116042000274087

Water Quality Interpretation. (2018). Water Quality Data, 71128.doi:10.1201/9780203734117-4

Weis, A. (n.d.). Lake Sampaloc - Philippines. Retrieved May, 2019, from

https://www.globalnature.org/en/living-lakes/asia/sampaloc

Weis, A. (2014). Threatened Lake of the Year 2014: Lake Sampaloc in Philippines. Retrieved

May 2019, from https://www.globalnature.org/36351/Living-

Lakes/Threatened-Lake-2018/Threatened-Lake-

2014/resindex.aspx

\section{APPENDIX}
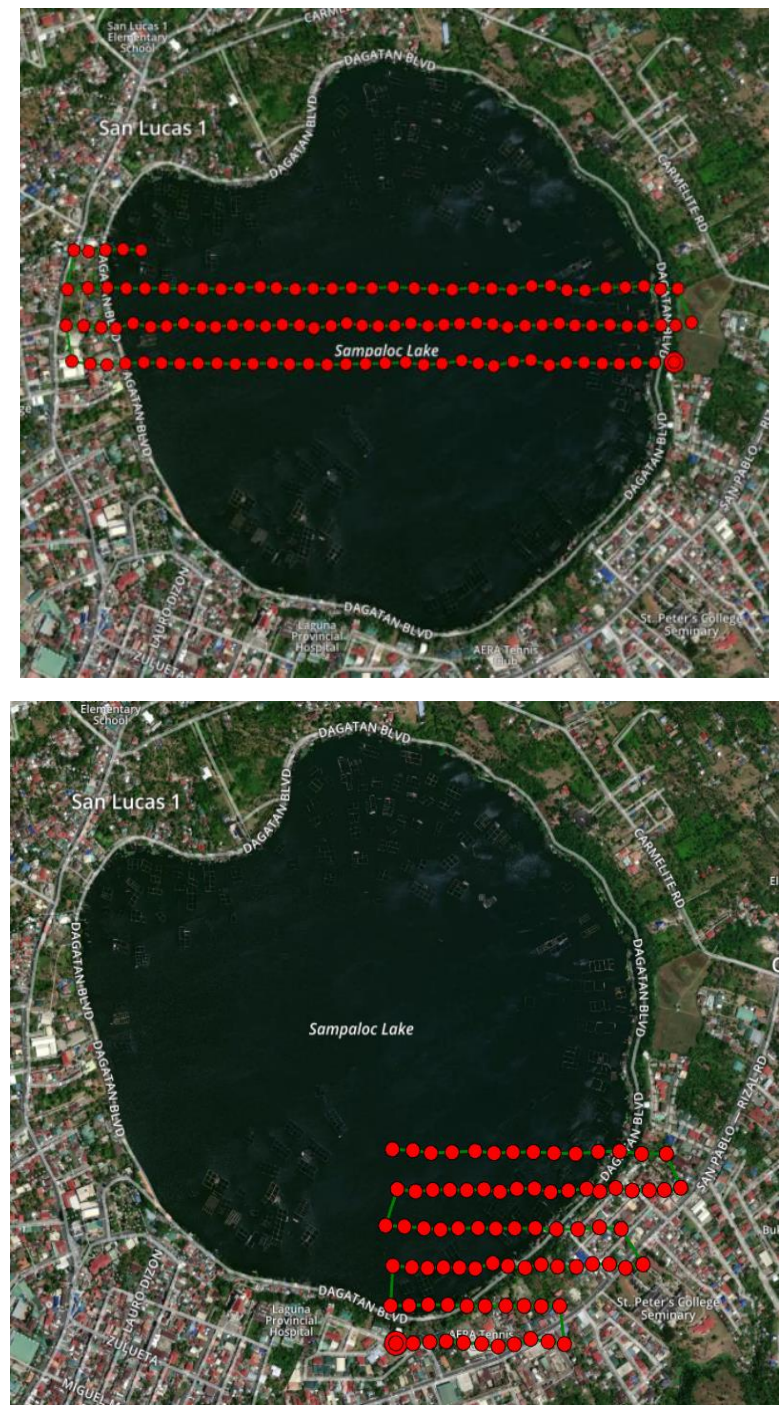
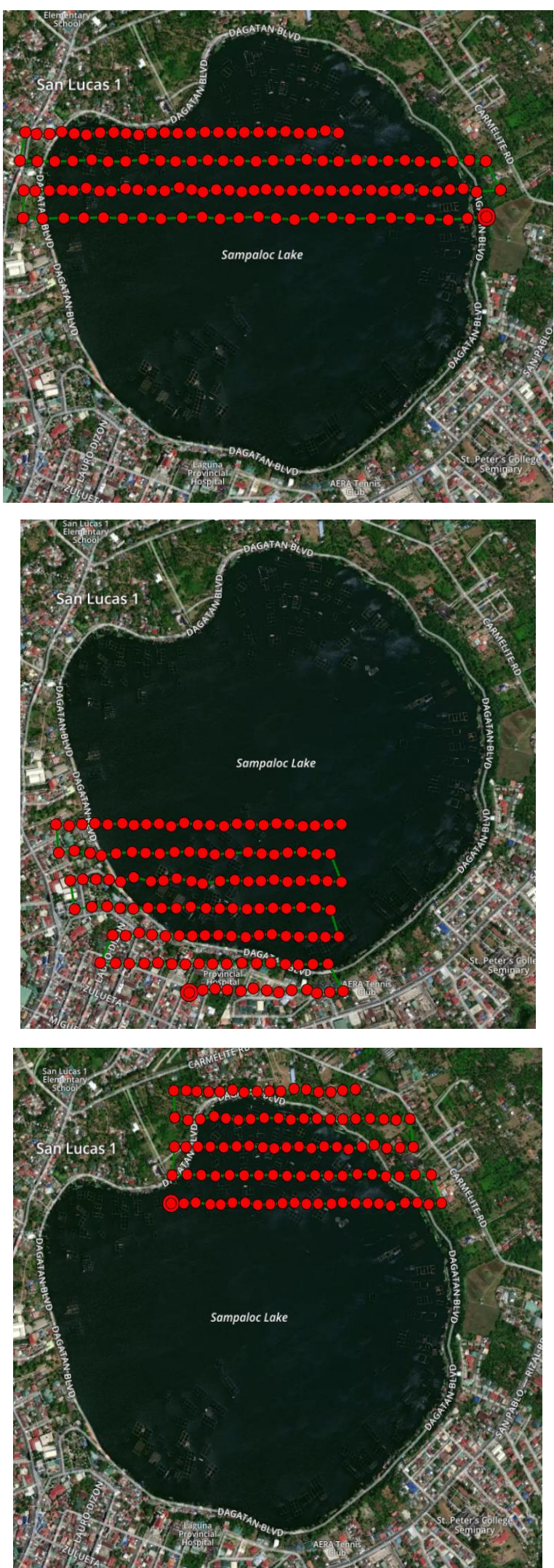